\title{
PENGUATAN PENGETAHUAN DAN KEAKTIFAN SADARI REMAJA PUTRI DI GRESIK
}

\author{
Luluk Yuliati $^{1}$, Nourma Yunita ${ }^{2}$, Twelvi Desimbriana ${ }^{3}$, Rizqi Aulia Savitri ${ }^{4}$ \\ 1,2,3,4 Fakultas Kesehatan Universitas Muhammadiyah Gresik \\ lulukyuliati@umg.ac.id,nourta83@umg.ac.id,twelvidsmbrn9781@gmail.com, \\ auliasavitri0718@gmail.com
}

\begin{abstract}
Active breast self-examination (BSE) is a major step in the early detection of breast cancer. It will give better results if the examination was done at young age. This research was conducted to find out what method was the most effective way to increase teenage's knowledge about early detection a breast cancer and the activity to do breast self-examination. This research was an experimental study using a research Post test only control group design. 40 female students were divided into 4 groups: negative control group, P1 group (video method), P2 group (demonstration method), P3 group (video and demonstration method). Data were tested using general multivariate analyze manova one way and continued testing with Duncan method. The results show that providing education with video methods, demonstrations or a combination of both can increase students' knowledge about BSE and the activeness of students doing BSE. The most effective educational method for increasing knowledge is video as the media with a value of $p=0,002$, while for the most effective educational method for increasing student activity in doing $B S E$ was a combination of video and demonstration methods with $p<0,0001$. Efforts to improve the behavior of adolescents who are aware of their reproductive health still need to be improved, the use of other active and interesting methods can be tried to continue and to be developed.
\end{abstract}

\section{Keywords: Effectiveness, Method, Education, BSE}

\section{PENDAHULUAN}

Kanker payudara adalah pembelahan dan penumpukan sel-sel di kelenjar, saluran dan jaringan yang ada di payudara. Pembelahan sel di dalam jaringan ini bisa menjadi sangat cepat sehingga sel-sel yang terbentuk menumpuk dan menyebabkan timbulnya massa atau benjolan (Smeltzer, S. C. d \& Bare, 2002).

Di Indonesia kasus kanker payudara menduduki peringkat pertama dari seluruh penyakit kanker yaitu sejumlah 58.256 kasus (16,7\%) (WHO, 2018). Berdasarkan data dari Kementrian Kesehatan didapatkan bahwa di
Indonesia kasus kanker payudara adalah sebesar 42,1 orang per 100.000 penduduk. Angka kematian akibat kanker mencapai 17 orang per 100.000 penduduk (Riskesdas, 2019). Jawa timur angka kejadian kanker payudara mencapai 12.186 kasus. Riset Kesehatan Dasar Tahun 2018 menunjukkan prevalensi kanker di Jawa Timur adalah 2,2 per 1.000 penduduk (Riskesdas, 2019).

Upaya pencegahan yang dapat dilakukan adalah memeriksa payudara sendiri (SADARI) dan pemeriksaan payudara klinis (SADANIS) di fasilitas kesehatan. SADARI menjadi metode 
deteksi yang sangat mudah dan murah untuk dilaksanakan sendiri. Hasil penelitian menemukan bahwa upaya pencegahan akan memberikan hasil lebih efektif jika dimulai sejak dini yaitu di usia remaja (GA.Colditz \& Kari Bohlke, 2015). Namun, para remaja perempuan cenderung kurang mengetahui bagaimana cara melakukannya, dan hasil penelitian telah menunjukkan bahwa salah satu penyebab kegagalan untuk melakukan SADARI adalah kurangnya pengetahuan dan kesadaran bagaimana melakukannya (Abolfotouh et.al, 2015).

Hasil survei awal di SMP N 20 Gresik dari 10 remaja yang diberikan pertanyaan tentang deteksi dini kanker payudara, lebih dari separuhnya (80\%) tidak mengetahui bagaimana cara melakukan deteksi dini kanker payudara. Sehingga penelitian dilakukan untuk mengetahui bagaimana efektivitas metode edukasi tentang deteksi dini kanker payudara terhadap peningkatan pengetahuan dan keaktifan remaja untuk melakukan SADARI.

\section{METODE}

Jenis penelitian True Experimental dengan menggunakan desain penelitian Post test only control group design. Populasi pada penelitian ini adalah siswi SMPN 20 Gresik yang berumur antara 12-14 tahun yang berjumlah 40 orang.
Teknik sampling untuk pengambilan sampel dengan menggunakkan teknik simple random sampling. Besar sampel menggunakkan rumus Federer dengan hasil minimum besar sampel dalam setiap kelompok adalah 4, jumlah tersebut ditambah $10 \%$ untuk mengantisipasi hilangnya sampel sehingga didapatkan 10 subjek dalam setiap kelompoknya. Sampel akan dibagi menjadi 4 kelompok perlakuan yaitu kelompok pertama adalah kelompk kontrol negatif, kelompok kedua adalah kelompok yang diberikan pendidikan dengan metode video, kelompok ketiga adalah kelompok yang diberikan pendidikan dengan metode demonstrasi dan yang terkahir adalah kelompok yang diberi video dan demontrasi. Alat ukur yang digunakan adalah kuesioner standar yang terdiri dari penilaian pengetahuan dengan bentuk pilihan ganda 25 soal dan keaktifan melakukan SADARI dengan bentuk angket skala likert 1-5 sejumlah 15 penyataan. Instrumen ini dikembangkan berdasarkan survei literatur dengan koefisien reliabilitas instrumen yang diukur adalah 0,9 yang menunjukkan reliabilitas yang baik dan diujikan pada 10 orang siswa yang tidak digunakan sebagai subjek penelitian.

Data yang diperoleh diolah dan dianalisis deskriptif untuk mengetahui karakteristik sampel penelitian. Analisis 
analitik dilakukan dengan untuk menguji pengaruh perlakuan secara simultan menggunakan uji statistik general multivariat anayzise manova one way (MANOVA), dengan tingkat kepercayaan 95\%, dan untuk melihat pengaruh setiap perlakuan menggunakkan uji lanjut POST HOC dengan metode Duncan dengan tingkat kepercayaan $95 \%$.

\section{HASIL DAN PEMBAHASAN}

Analisis Deskriptif dari hasil pengolahan data pengetahuan dan keaktifan remaja putri dalam Gambar 1 menunjukkan bahwa nilai paling tinggi untuk pengetahuan ada pada kelompok video $(81,16)$, sedangkan pada keaktifan SADARI berada di kelompok video dan demonstrasi $(57,6)$.

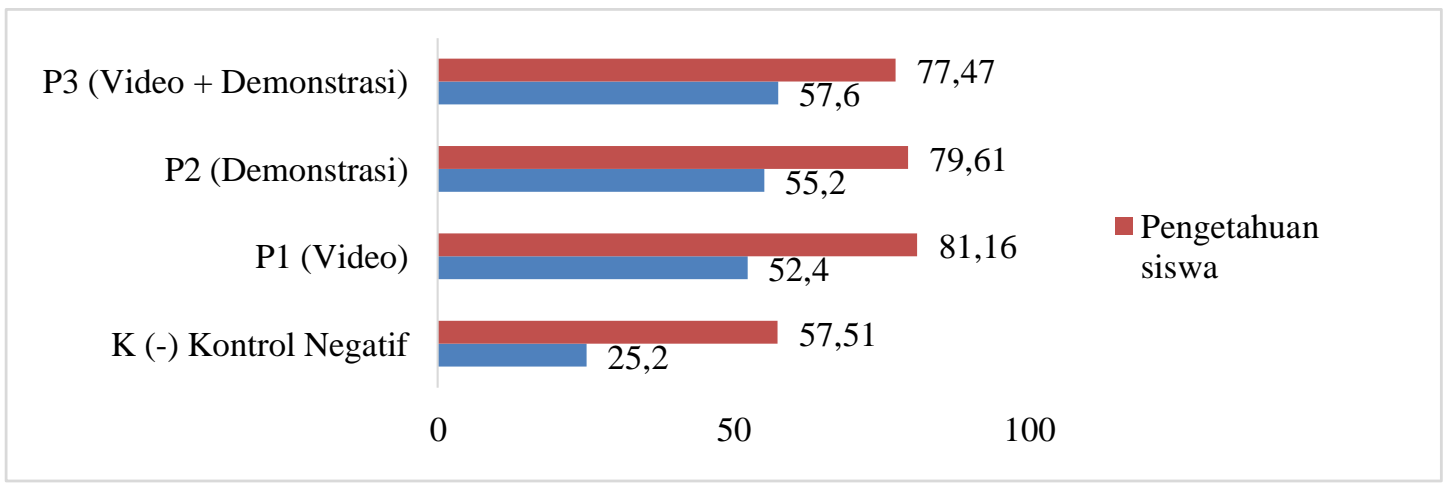

Gambar 1. Perbedaan Pengaruh Setiap metode

Efektifitas Edukasi Terhadap perbedaan yang signifikan dari berbagai Peningkatan Pengetahuan dan metode edukasi yang diberikan terhadap Keaktifan SADARI Remaja Putri

Uji MANOVA dalam penelitian ini digunakan untuk melihat pengaruh edukasi terhadap pengetahuan deteksi dini kanker payudara dengan keaktifan melakukan SADARI secara bersama sama.

Tabel 1. Hasil analisis Uji MANOVA

\begin{tabular}{lc}
\hline Multivariat & Sig. \\
\hline Pillai's trace & $<0,0001$ \\
Wilks' lambda & $<0,0001$ \\
Hotelling's trace & $<0,0001$ \\
Roy's largest root & $<0,0001$ \\
\hline \multicolumn{2}{c}{ Hasil tes menunjukkan nilai } \\
p $<0,0001$ yang berarti $\quad$ terdapat
\end{tabular}
pengetahuan deteksi dini kanker payudara dengan keaktifan melakukan SADARI pada remaja putri.

Hasil penelitian menunjukkan bahwa pemberian edukasi efektif dalam meningkatkan pengetahuan dan keaktifan SADARI remaja putri secara bersamaan. Hal ini sesuai dengan hasil penelitian (Abera.Hiwot et.al, 2017). yang menyatakan bahwa pemberian edukasi merupakan cara efektif untuk meningkatkan pengetahuan dan kemampuan melakukan SADARI pada 
siswa perempuan (Abera.Hiwot et.al, 2017).

Perilaku aktif melakukan SADARI secara teratur terbentuk dari pengetahuan, sikap dan pengalaman yang telah didapatkan tentang deteksi dini kanker payudara sebelumnya, hal ini sesuai dengan penelitian Yoong.NT\&Soon.LK， (2017) yang menyimpulkan bahwa sesi pendidikan tentang SADARI terbukti efektif dalam meningkatkan pengetahuan dan praktik SADARI pada mahasiswi (Yoong.NT\&Soon.LK, 2017).

Dari hasil penelitian lain menyatakan bahwa pemberian edukasi akan memberikan hasil yang efektif jika dimulai dari sejak dini yaitu pada usia remaja (GA.Colditz \& Kari Bohlke, 2015). Edukasi deteksi dini kanker payudara merupakan upaya promotif yang bertujuan untuk menurunkan angka kesakitan dan kematian akibat kanker payudara. Siswa sekolah menengah pertama masuk dalam kelompok remaja awal yang mengalami perubahan anatomi dan fisiologi organ seksual secara cepat sehingga kelompok remaja awal ini perlu untuk diberikan edukasi.

Pemberian edukasi pada usia dini khususnya pada kelompok remaja awal merupakan langkah strategis sebagai upaya preventif karena diharapkan apabila pada usia remaja sudah memiliki pengetahuan dan keaktifan dalam mendeteksi adanya kelainan pada payudara mereka maka gejala awal dari kanker payudara dapat dideteksi sejak dini sehingga efek buruk dapat dicegah dan kemungkinan untuk sembuh lebih tinggi.

\section{Pengetahuan}

Untuk melihat pengaruh edukasi terhadap masing-masing variabel independen bisa dilihat di Tests of Between-Subjects Effects.

Tabel 2. Hasil Tests of Between-Subjects Effects

\begin{tabular}{lc}
\hline \multicolumn{1}{c}{ Model } & P-Value \\
\hline Pengetahuan & 0,002 \\
Keaktifan melakukan & $<0,0001$ \\
SADARI &
\end{tabular}

SADARI

Berdasarkan Tabel 2. dapat diketahui bahwa terdapat perbedaan yang signifikan dari pengetahuan dan keaktifan melakukan SADARI pada remaja setelah pemberian edukasi dengan nilai $\mathrm{P}<0,005$.

Hasil penelitian menunjukkan bahwa tingkat pengetahuan siswa yang diberikan edukasi mengalami peningkatan dibanding dengan siswa yang tidak diberikan edukasi. Hasil ini sesuai dengan penelitian Khiyali Zahra et al., (2017) yang menyatakan bahwa pengetahuan siswa pada kelompok dengan metode video, demonstrasi, dan kombinasi memiliki nilai rata-rata lebih tinggi dibandingkan dengan kelompok kontrol negatif (Ibitoye, 2019; Khiyali Zahra et al., 2017) . 
Dalam penelitian ini mendapatkan bahwa pemberian edukasi dapat meningkatkan pengetahuan sebanyak 74\% pada kelompok yang diberikan edukasi dengan metode video dibanding dengan kelompok yang tidak diberikan edukasi, hasil ini diperkuat dengan penelitian Yong (2017) yang menyebutkan bahwa pengetahuan siswa meningkat sebesar $65 \%$ sebelum dan sesudah diberikan intervensi (Yoong.NT \&Soon.LK, 2017).

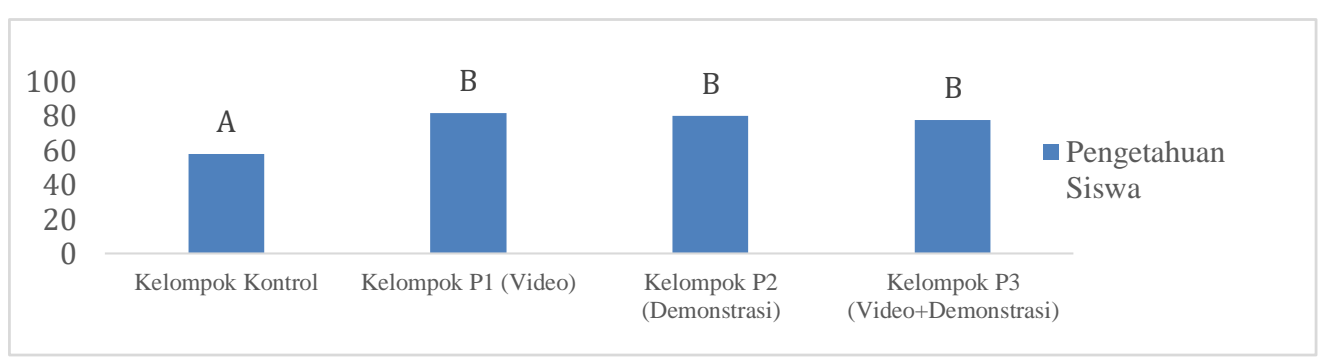

Gambar 2. Diagram rerata skor pengetahuan dan hasil uji beda Duncan

Seluruh metode edukasi yang
digunakan dapat meningkatkan pengetahuan secara signifikan walaupun nilai peningkatan pengetahuan masingmasing kelompok tidak terpaut jauh dan berada dalam kelompok subset yang sama (Gambar 2). Hasil ini dikuatkan dengan penelitian Abera (2017) yang menyatakan bahwa pemberian edukasi dengan metode kombinasi antara diskusi, video demonstrasi dan praktikum merupakan metode yang paling efektif dalam meningkatkan pengetahuan siswa tentang SADARI (Abera.Hiwot et.al, 2017).

Penggunaan berbagai macam metode dilakukan untuk mengetahui metode manakah yang paling efektif untuk meningkatkan pengetahuan tentang deteksi dini kanker payudara dengan keaktifan melakukan SADARI pada remaja putri. Hal ini dilakukan sebagai upaya meningkatkan kesadaran remaja putri tentang pentingnya menjaga kesehatan reproduksinya. Pemberian edukasi mengenai deteksi dini kanker payudara harus diberikan bersama dengan bagaimana cara melakukan deteksi dini kanker ini secara mandiri, sehingga setelah subjek mengetahui apa saja komplikasi yang dapat timbul dari penyakit ini dan bagaimana deteksi dini yang efektif, mereka akan cenderung untuk lebih aktif melakukan SADARI sebagai upaya deteksi dini secara mandiri.

\section{Keaktifan SADARI}

Hasil uji analisis menunjukkan bahwa setiap metode memiliki pengaruh yang signifikan yaitu metode terhadap pengetahuan dengan P:0,002 dan metode Keaktifan melakukan SADARI dengan $\mathrm{P}<0,0001$. 


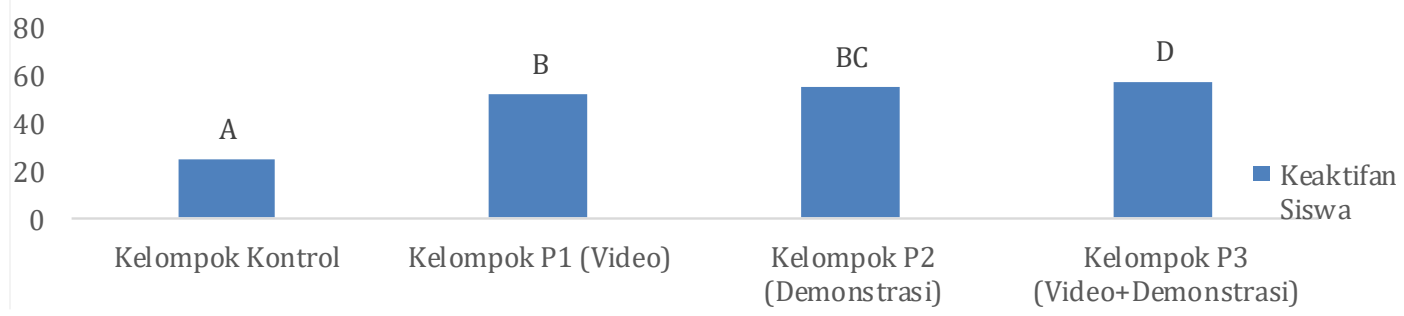

Gambar 3. Diagram rerata skor keaktifan siswa dan hasil uji beda Duncan

Hasil penelitian menunjukkan bahwa tingkat keaktifan siswa untuk melakukan SADARI mengalami peningkatan setelah diberikan edukasi. Hal ini sesuai dengan penelitian Yong (2018) yang menyimpulkan bahwa pendidikan kesehatan tentang SADARI terbukti efektif dalam meningkatkan praktik SADARI pada mahasiswi (Yoong.NT\& Soon.LK, 2017).

Hasil penelitian ini menunjukkan bahwa pemberian edukasi dapat meningkatkan keaktifan melaksanakan SADARI sejumlah $44 \%$ pada kelompok yang diberikan edukasi dengan metode kombinasi video dan demonstrasi dibanding dengan kelompok yang tidak diberikan edukasi, hal ini sejalan dengan penelitian Sama et.al (2017) yang menunjukkan bahwa setelah sesi edukasi $30 \%$ peserta kelompok eksperimen mulai berlatih SADARI secara rutin (Carlson-Babila Sama et.al, 2017).

Metode edukasi yang paling efektif untuk meningkatkan keaktifan melakukan SADARI adalah metode kombinasi video dan demonstrasi
(Gambar 3). Pada metode video atau demonstrasi tidak menunjukkan peningkatan keaktifan yang signifikan dari pada metode kombinasi video dan demonstrasi, masing-masing metode berada dalam kelompok subset yang berbeda.

Pemberian edukasi dapat meningkatkan keaktifan melakukan SADARI pada siswa, karena dengan pemberian edukasi tingkat pengetahuan siswa menjadi lebih baik sehingga kesadaran melakukan SADARI lebih meningkat. Perilaku baru terbentuk dimulai dari perubahan pengetahuan, dalam artian siswa menjadi lebih tahu dan paham tentang pentingnya deteksi kanker payudara. Hasil dari pengalaman belajar yang didapat akan membentuk sikap remaja yang pada akhirnya menimbulkan perubahan perilaku untuk melakukan SADARI secara mandiri dan teratur untuk menjaga kesehatan reproduksinya. 


\section{KESIMPULAN DAN SARAN}

Pemberian edukasi terbukti efektif dalam meningkatkan Pengetahuan Deteksi Dini Kanker Payudara dan Keaktifan SADARI Remaja Putri secara bersama-sama dengan nilai $\mathrm{p}<0,0001$.

Metode edukasi video yang terbukti paling efektif untuk meningkatkan Pengetahuan Deteksi Dini Kanker Payudara dengan nilai $\mathrm{p}<0,002$.

Metode edukasi kombinasi video dan demonstrasi adalah yang paling efektif untuk meningkatkan keaktifan melakukan SADARI pada remaja putri dengan nilai $\mathrm{p}<0,0001$.

Peningkatan perilaku remaja yang sadar akan kesehatan reproduksinya masih perlu untuk terus ditingkatkan, masih banyak metode lain yang bisa diterapkan untuk lebih memaksimalkan hasil yang diharapkan yaitu remaja lebih peduli dan aktif dalam mencari informasi dan aktif melakukan kegitan yang dapat meningkatkan kesehatan reproduksinya.

\section{DAFTAR PUSTAKA}

Abera.Hiwot et.al. (2017). Effectiveness of planned teaching intervention on knowledge and practice of breast self-examination among first year midwifery students. Plos One Journal, 12(9), 1-9. Retrieved from

https://journals.plos.org/plosone/ar ticle/file?id=10.1371/journal.pone. 0184636\&type $=$ printable

Abolfotouh et.al. (2015). Using the health belief model to predict breast self examination among Saudi women. BMC Public Health, 15(1163), $1-12$. https://doi.org/10.1186/s12889-

015-2510-y

Carlson-Babila Sama et.al. (2017). Awareness of Breast Cancer and Breast Self-Examination Among Female Undergraduate Students in a Higher Teachers Trainning College In Cameroon. The Pan African Journal, 28. Retrieved from https://www.panafrican-medjournal.com/content/article/28/91/p df/91.pdf

GA.Colditz \& Kari Bohlke. (2015). Preventing Breast Cancer Now By Acting On What We Already Know. Nature Partner Journal Breast Cancer. Retrieved from https://www.nature.com/articles/np jbcancer20159.pdf

Ibitoye, o \& T. (2019). The Impact of Education Knowledge Attitude and Practice of Breast SelfExamination Among Adolescents Girls at The Fiwasaye Girls Grammer School Akure, Nigeria. 36, 39-46. Retrieved from https://pubmed.ncbi.mlm.nih.gov/3 1377988/ 
Khiyali Zahra et al. (2017). Educational intervention on Breast SelExamination Behavior in Women Referred To Health Centers: Application of Health Belie Model. Asian Pacific Journal of Cancer Prevention, 18(10), 2822-2838. Retrieved from https://www.ncbi.nlm.nih.gov/pmc /articles/PMC5747411/pdf/APJCP18-2833.pdf

Riskesdas. (2019). Laporan Nasional Riskesdas 2018 Badan Penelitian dan Pengembangan Kesehatan. In Lembaga Penerbit Badan Penelitian dan Pengembangan Kesehatan (LPB) (Vol. 3).

Smeltzer, S. C. d \& Bare, B. G. (2002). Buku Ajar Keperawatan Medikal Bedah Brunner \& Suddarth. Jakarta: EGC.

WHO. (2018). The International Agency for Research on Cancer (IARC). Retrieved from https://www.who.int/ionizing_radi ation/research/iarc/en/

Yoong.NT\&Soon.LK. (2017). The Effects Of Educational Intervention On Knowledge And Practice Of Breast SelfExamination Among Female College Students. International Journal of Public Health and Clinical Sciences (IJPHCS), 4(120-131). Retrieved from http://publichealthmy.org/ejournal/ ojs2/index.php/ijphcs/article/view/ 530 